\title{
REMEMBERING WIM COHEN
}

\author{
RYSZARD SYSKI \\ Department of Mathematics \\ University of Maryland \\ College Park, MD 20742
}

(Received January, 2001; Revised February, 2001)

This article is a short biographical account on deceased Jacob Willem Cohen.

Key word: Biography.

AMS subject classifications: $01-00,01-02$.

There are situations, which at the time of their occurrence seem to be ordinary and usual, but whose significance becomes apparent only later, after the passage of many years.

This thought struck me as I looked at a photo of the "Three Musketeers", namely Wim Cohen, Julian Keilson and myself, taken in 1971 at the Rochester Conference. None of us thought that I would be the last to remain alive today. I met Julian at the Chapel Hill Conference in Queueing Theory in 1964 and described our life-long friendship in my "In Memoriam" [6]. My friendship with Wim, which started from the 50's when I was still in London, was described by Wim himself in his article about me in the Special Issue of JAMSA [1]. Here is an excerpt:

In June 1955, I received a letter from Harrow, England. ... I looked forward to meeting its author. We met in Copenhagen and that encounter was the start of a lasting and most rewarding friendship.

I feel it is my privilege and duty to my friend to give a brief account of our friendship. This may be regarded as a personal supplement to the book, Liber Amicorum for J.W. Cohen edited by Onno Boxma and myself $[2,3]$.

Wim was an excellent mathematician, serious in his research, demanding high standards from himself and his students, "not taking fools gladly", yet he was a good person with a sense of humor, and ... a heavy pipe smoker.

His son Arjon spoke these words about his father at the funeral:

To provide for his family was my father's desire - to some extent, this sums him up .... For him providing for his family was not just provid- 
ing material security, but was about providing the framework, which unifies and perpetuates a family.

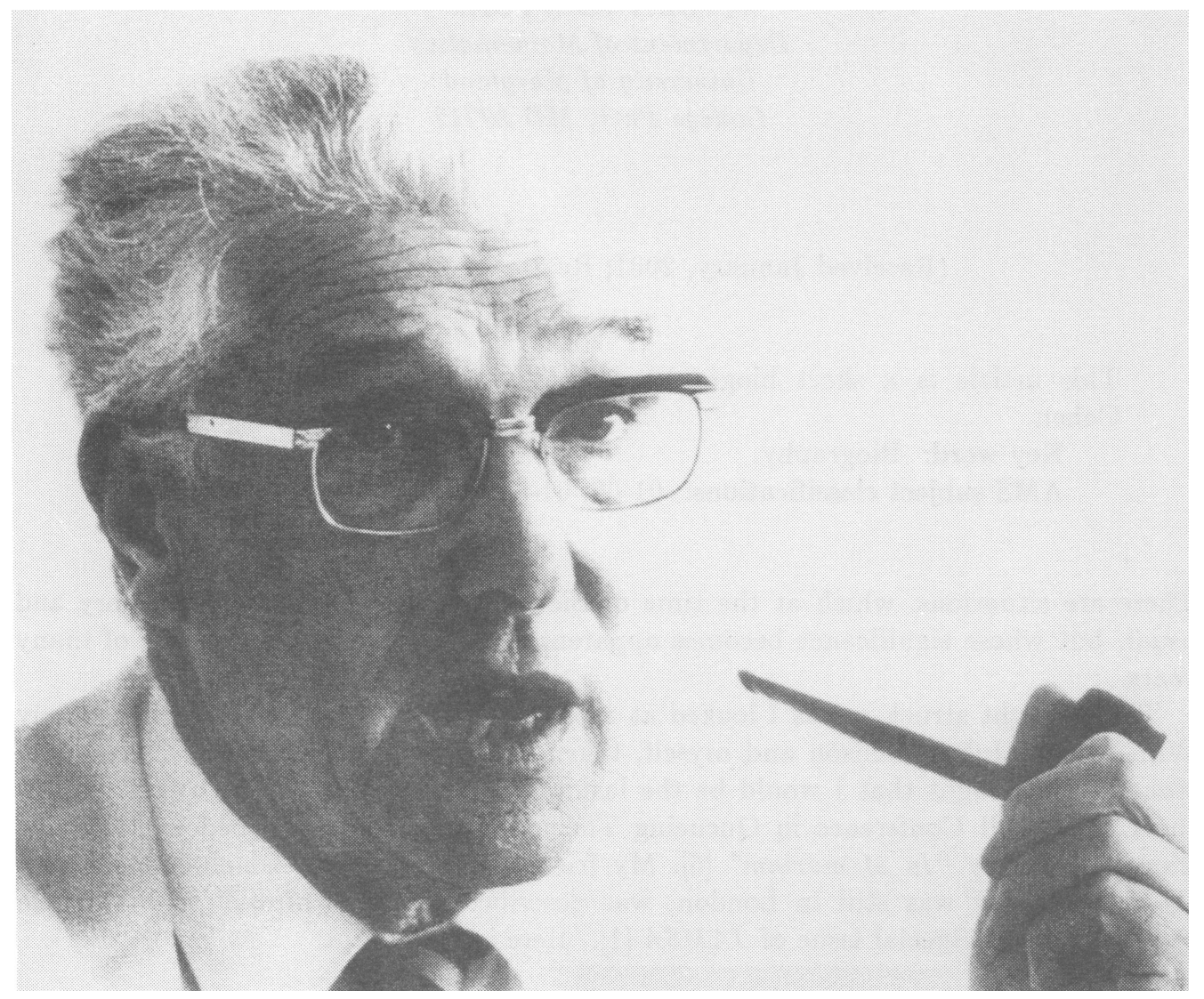

Jacob Willem Cohen (August 8, 1923-November 12, 2000)

Wim's contributions to Applied Probability and, especially, to Queueing Theory, are well recognized by the scientific community. Significance and influence of his work has been stressed by many researchers and is well documented. It is not my intention to repeat what others have written, but rather wish to record my personal impressions. His excellent treatise on The Single Server Queue (1982 second edition) extends the powerful Pollaczek's method and shows its suitability for discussion of real problems; moreover, it gained him a well-deserved nickname "a single-server man." His joint work with Onno Boxma on Boundary Value Problems in Queueing System Analysis illustrates Wim's interest in treating queueing as a boundary value problem using complex analysis. This fruitful approach resulted in a series of papers by Wim and his students, and culminated in his book on Analysis of Random Walks (IOS Press, 1992) dedicated to his close collaborator Onno J. Boxma. Boundary problems was a topic to which Wim devoted the last years of his life.

There were two areas concerning organizational activities which were of mutual interest to Wim and myself. These were the International Teletraffic Congresses 
(ITC) and Stochastic Processes and Their Applications (SPATA) (both conferences and journals of the same name). History of their origins and early development may be found in my paper, "A personal view of queueing theory" [5]; see also the autobiographical articles of Wim and myself in The Craft of Probabilistic Modeling [4]. These two organizations are nowadays not what they used to be in the old times.

At the first ITC meeting held in Copenhagen in 1955, Wim and I became members of the library committee. The committee had several meetings, of which the most interesting was that in Paris at the next ITC. We met there with Pierre Le Gall and his charming wife Christiane, forming our lasting friendship. We met subsequently at various ITC meetings all over the world. Both Wim and Pierre moved up in ranks within ITC, serving on their prestigious committees and boards. In 1977, we met again at an informal and moving ceremony, among close friends in the hospitable home of Christiane and Pierre Le Gall, in a scenic countryside of Normandy. In his testimonial speech, Wim presented Felix Pollaczek with the gold medal on behalf of ORSA/TIMS, which awarded Pollaczek the John von Neumann Theory Prize, and offered him congratulations to Mr. and Mrs. Pollaczek.

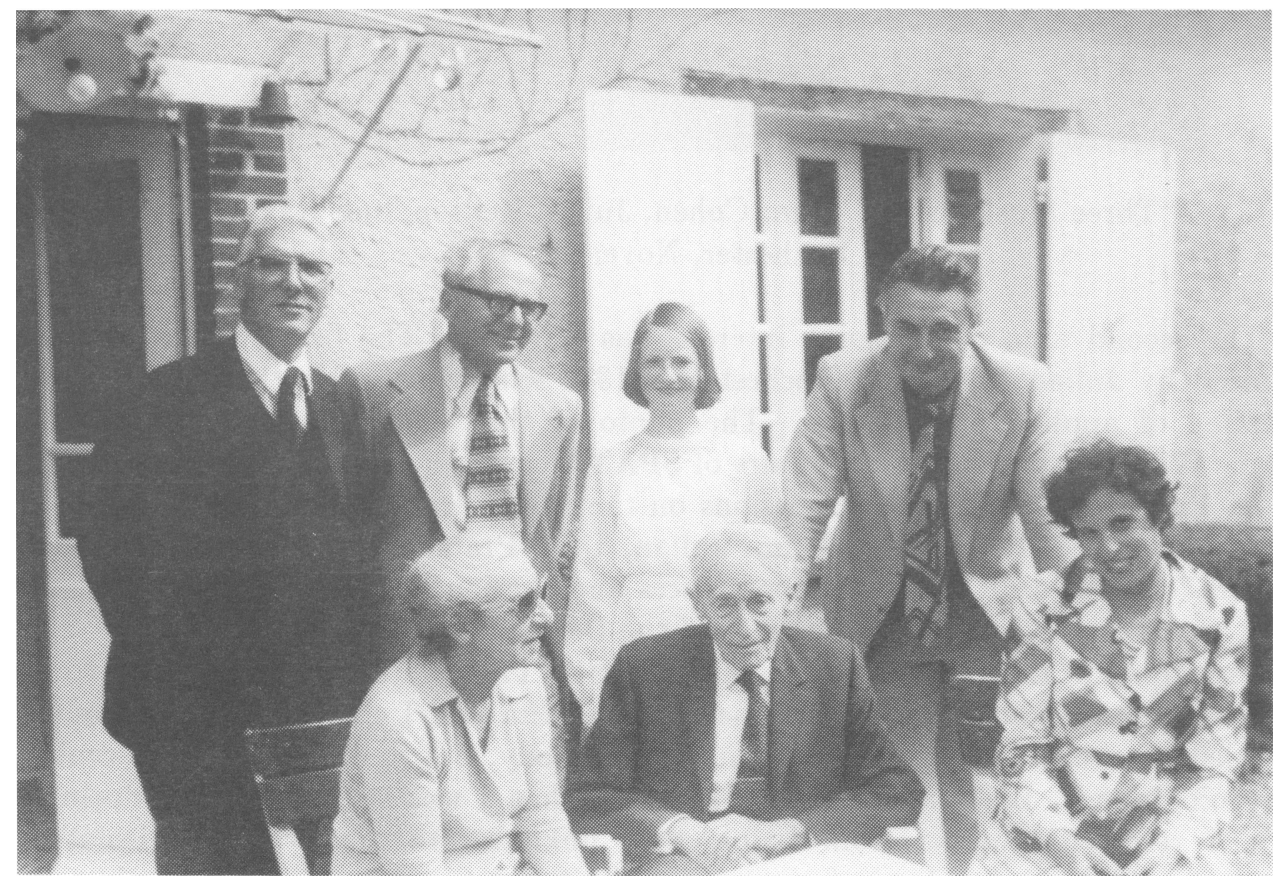

Pierre Le Gall's summer home, Boi-le-Roi, 1977

Sitting: Mrs. Vera Pollaczek, Felix Pollaczek, and Annette Cohen-Waterman. Standing: Wim Cohen, Ryszard Syski, Claire Le Gall and Pierre Le Gall.

Later, on invitation of F. Schreiber (who served as the principal editor), Wim, Pierre, Paul Kuhn, and myself, contributed to the Special Issue in Memory of Felix Pollaczek ( $A E U, 1993)$. Wim published also an obituary of Felix Pollaczek. The last ITC, which Wim and I attended together, was in 1997 in Washington (as my friends said jokingly, that ITC came to me, not the other way around) when Wim presented a paper on his research. 


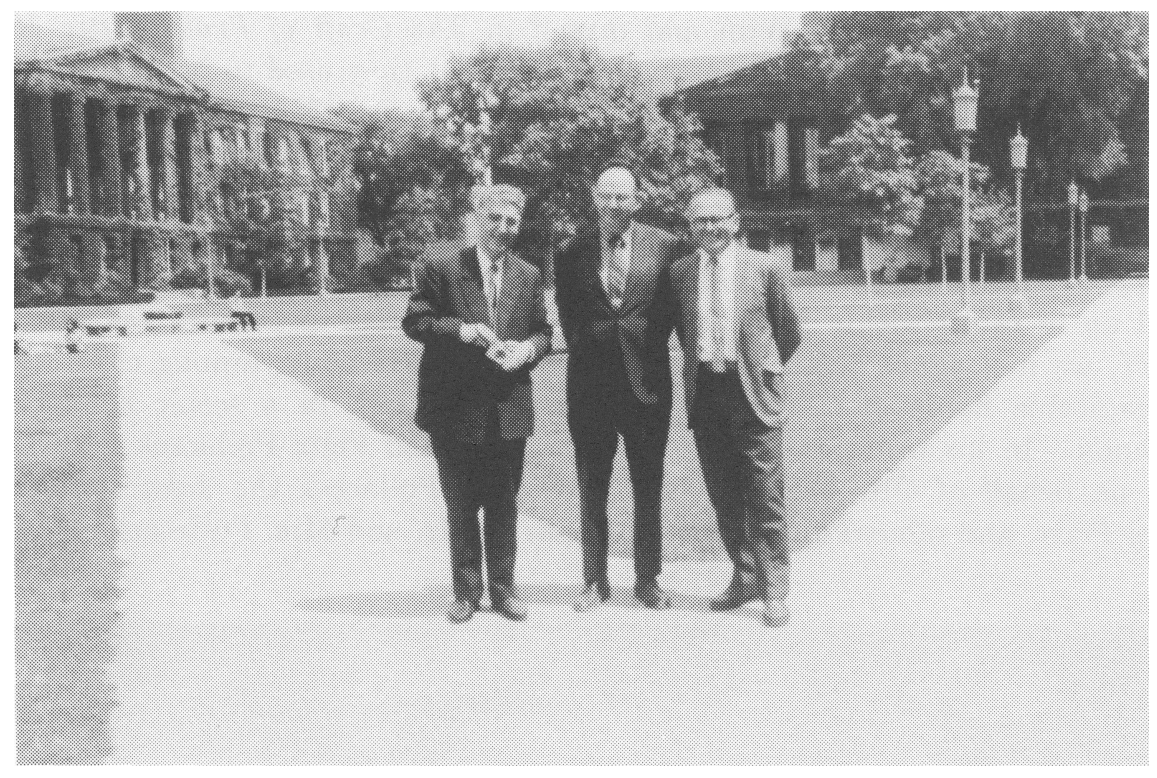

"Three Musketeers": Wim Cohen, Julian Keilson, and Ryszard Syski Rochester, November 1971.

The second area of our joint interest was SPATA. The first conference was organized by Julian Keilson in Rochester in 1971 who rightly felt the need for such a meeting of applied probabilists. The photo of the "Three Musketeers" was taken then. Wim was very active in affairs of SPATA conferences in subsequent years.

At Rochester, we started discussions on the new journal, also called SPATA. The first issue appeared in 1973: Wim, Julian, Uma Prabhu, and I being its "founding fathers." At present, both, the conferences and the journal are out of our hands, but they are doing well under the auspices of the Bernoulli Society.

Participation in activities of the ITC and SPATA gave us an opportunity to meet with old friends and to meet new ones. Both Wim and I cherished such encounters. The list of names is too long to mention everybody, but it is impossible to omit our very old friends, Lajos and Dalma Takács. When I was still in London during the 50 's, I received a paper from Lajos, then unknown to me, who was isolated in Hungary. This was a classical example of an independent work, as the problem had been already treated by Wim; so, it was natural to have these two mathematicians get together. In 1958, Lajos was able to leave Hungary. Then in London he met and married Dalma and subsequently emigrated to the United States. The rest is history.

Through all these years, I have had many opportunities to meet with Wim and the memory of these meetings will always stay alive! We used to talk a lot about mathematics, family and current events - actually, it was he who did most of the talking. We have been in correspondence and exchanged papers and ideas. I have an enormous collection of his letters, papers, reports and reprints, including books. I visited Wim in The Hague on several occasions and always enjoyed a warm reception by him and Annette. On Wim's invitation, I spent my sabbatical semester in the 


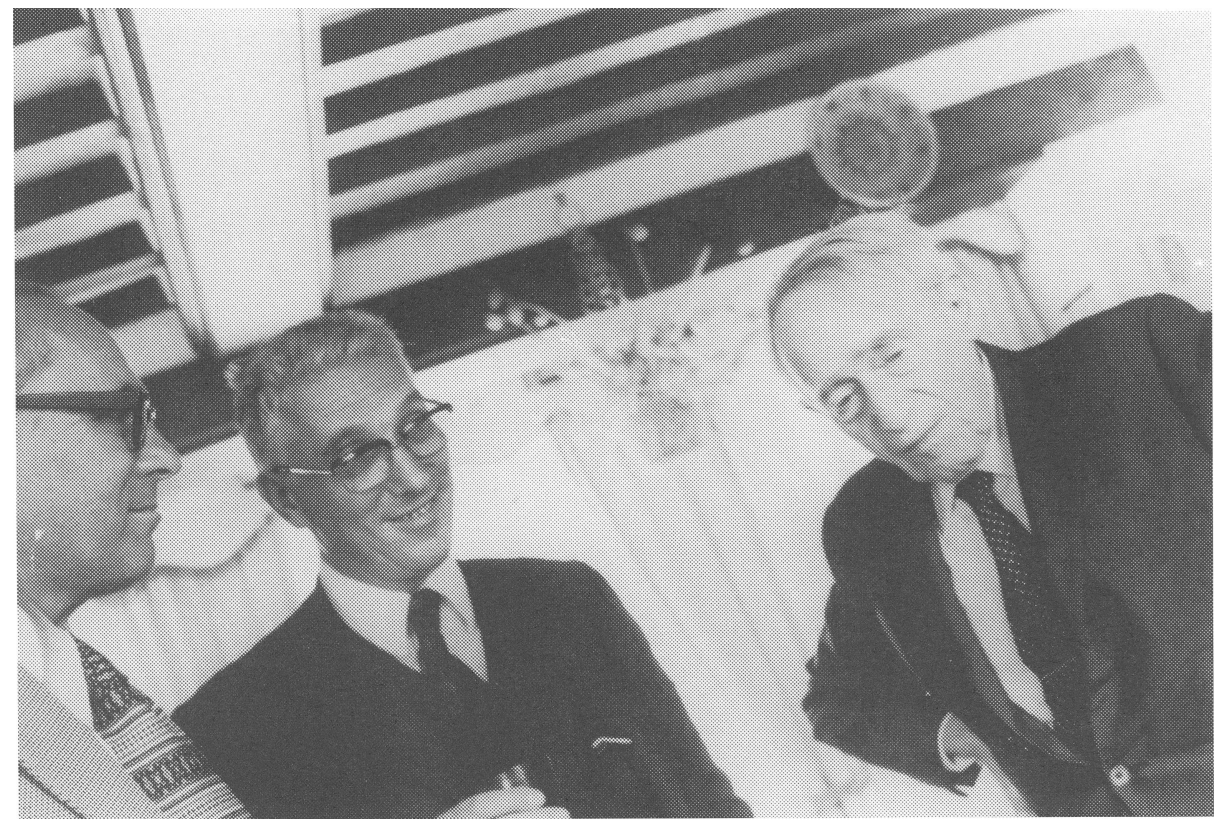

Ryszard Syski, Wim Cohen, and Felix Pollaczek, 1977.

Spring of 1986 hosted by the University of Utrecht where Wim has been employed for years. This was a remarkable time for me. I was invited to attend a formal doctoral examination, as a visiting faculty member. The ceremony took place in a 16th century building and although I did not understand a word of Dutch, I tried to look sufficiently dignified. At that time, Wim was involved in research on a stochastic identity, which he established in his work on boundary value problems and we talked a lot about it. Here his sense of humor manifested itself when he asked me "What do you think Frank Spitzer is doing these days?" Seeing my puzzled look, Wim answered himself, "He contemplates his identity." To satisfy my own university requirements, I wrote at Utrecht a technical report on "random walk with absorption", which interpreted Wim's approach in terms of potential theory. Let me mention here, that it was my pleasure to explain Wim's work - always with his blessing and support - earlier in 1961 in my talk on "Derived Markov Chains" at the meeting in Seattle, and more recently in 1992, in my paper "Exit time for positive quadrant for two dimensional Markov chain" (Stochastic Models, Special Issue in memory of our mutual friend, Micha Yadin 1992).

During my stay in Utrecht, Onno Boxma introduced me to his wife Jopie and their two lovely daughters. When driving in his car on our way to The Hague, he revealed to me his plans about Liber Amicorum for Wim and invited me to collaborate with him. So our work started and it took us two years to produce a volume.

Wim visited us in Maryland on many occasions either attending conferences or traveling with Annette to visit friends. He was invited by the University of Maryland several times to give a seminar in our department on his work. My colleagues remember him when during the hot summer, he was going for lunch with us wearing a coat and scarf. I remember driving him to the NBS when he was invited to speak 
there.

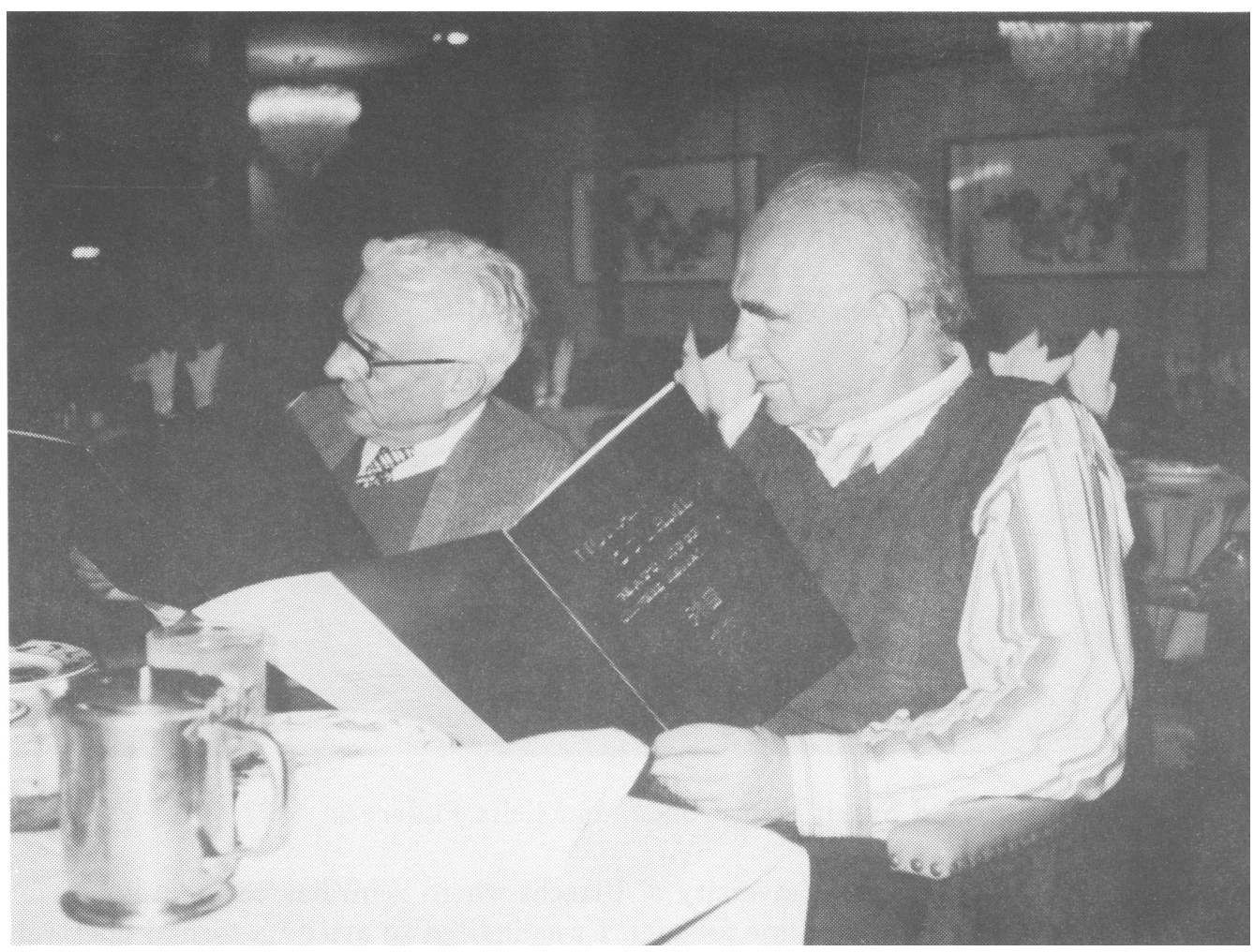

Wim Cohen and Ryszard Syski, 1977.

Among his numerous activities, Wim frequently organized conferences devoted to topics of current interest. Two of which I attended were: a seminar on Teletraffic Analysis at CWI (Amsterdam, June 1986) whose proceedings were edited by Onno Boxma, Wim Cohen and Henk Tijms, and Stochastic Modeling Workshop at ITC, Copenhagen 1991, whose proceedings are published as a part of Queueing, Performance and Control in ATM, edited by Wim Cohen and C.D. Pack. In turn, Wim, Julian Keilson, and Paul Kuhn were speakers at a session on "Recent Advances in Queueing Theory," which I organized at the ITC in Montreal during 1983.

Wim received numerous honors for his scientific work. Among others, in June 1988, he received a honorary doctorate from the Technion Institute of Technology. On his retirement (mandatory at age 65), his department in Utrecht organized a symposium in his honor in 1988. The book, Liber Amicorum, edited by Onno Boxma and myself (as I already mentioned), was presented to Wim. On the evening of September 1, there was a reception and dinner in a pleasant inn in the countryside near Utrecht. In a nice atmosphere, there were too many friends who wanted to speak: so the scheduled speakers (among whom was I) had their prepared speeches drastically reduced. (Afterwards, I gave Annette Cohen the text of my speech).

In the summer of 1992, when Wim's book and my book were published by IOS Press in Amsterdam, Dr. E. Fredriksson (Director of IOS) and his charming wife Zosia (whose father was a mathematics teacher at a local high school I attended in 
pre-war Poland!) invited Wim and Annette, myself, and my niece Malgosia (who came from Poland), to dinner in celebration of the occasion. This was a remarkable night.

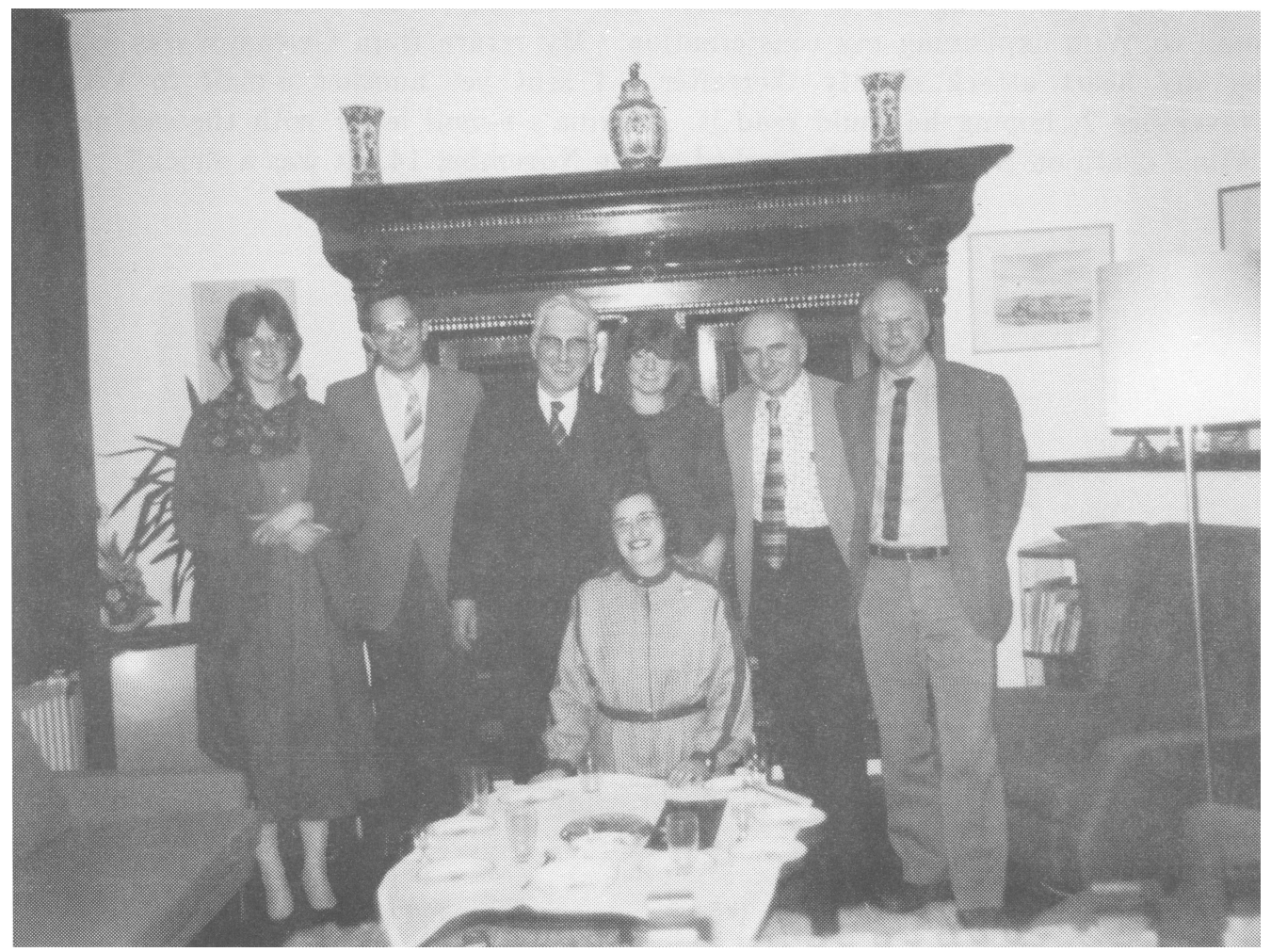

At the Cohen home (see Dutch wardrobe in the background).

Jopie Boxma, Onno Boxma, Wim, Mrs. Tijms, Ryszard Syski, and Henk Tijms.

Kneeling: Annette Cohen-Waterman (circa 1988).

During the second world war, a family who hid Wim from the Nazis, had a cleaning lady coming twice a week for several hours. In order for her not to know that they were hiding a Jew, Wim had to hide in a hole between the floors in complete darkness, laying there motionless. In order to overcome the boredom, he tried to solve mathematical problems blindfolded. He said he owed his interest in mathematics to these experiences. Wim was a very religious man and everyone who knew him, respected him for that. Perhaps it was also the results of these early encounters. He was an observant Jew, without making everyone around him uncomfortable.

Wim wrote on September 10, 1998, in response to my birthday greetings, "Yes, I have passed 75 . It is difficult to believe, but I cannot find an error in the proof, so I have to accept it, and I am glad with your congratulations."

In February 1999, he wrote to me that the radiation treatment was finished and that he feels much better; his doctors gave him good hope for the future. In subsequent letters, he was in a good mood. In May 2000, he informed me that he had been hospitalized for five weeks and he had an operation, but his condition was gradually improving. So we hoped for good and wished him a complete recovery. 
However, in August, he complained about losing the feeling in his right arm and concluded his letter, "I hope soon to be in contact with you again." On August 30, I was surprised to hear on the phone, the very weak voice of Wim. I realized that it was a good-by. I lost my presence of mind and in full confusion, I started talking about my forthcoming trip to Germany. The next day, when I recovered, I sent an email to Wim explaining my consternation. My return from Germany was followed by my heart attack shortly thereafter. I sent yet another e-mail to Wim on November 2, hoping he could read it. Boxma's e-mail letter with the sad news of Wim's death on November 12, reached me on November 14. It was a shock!!

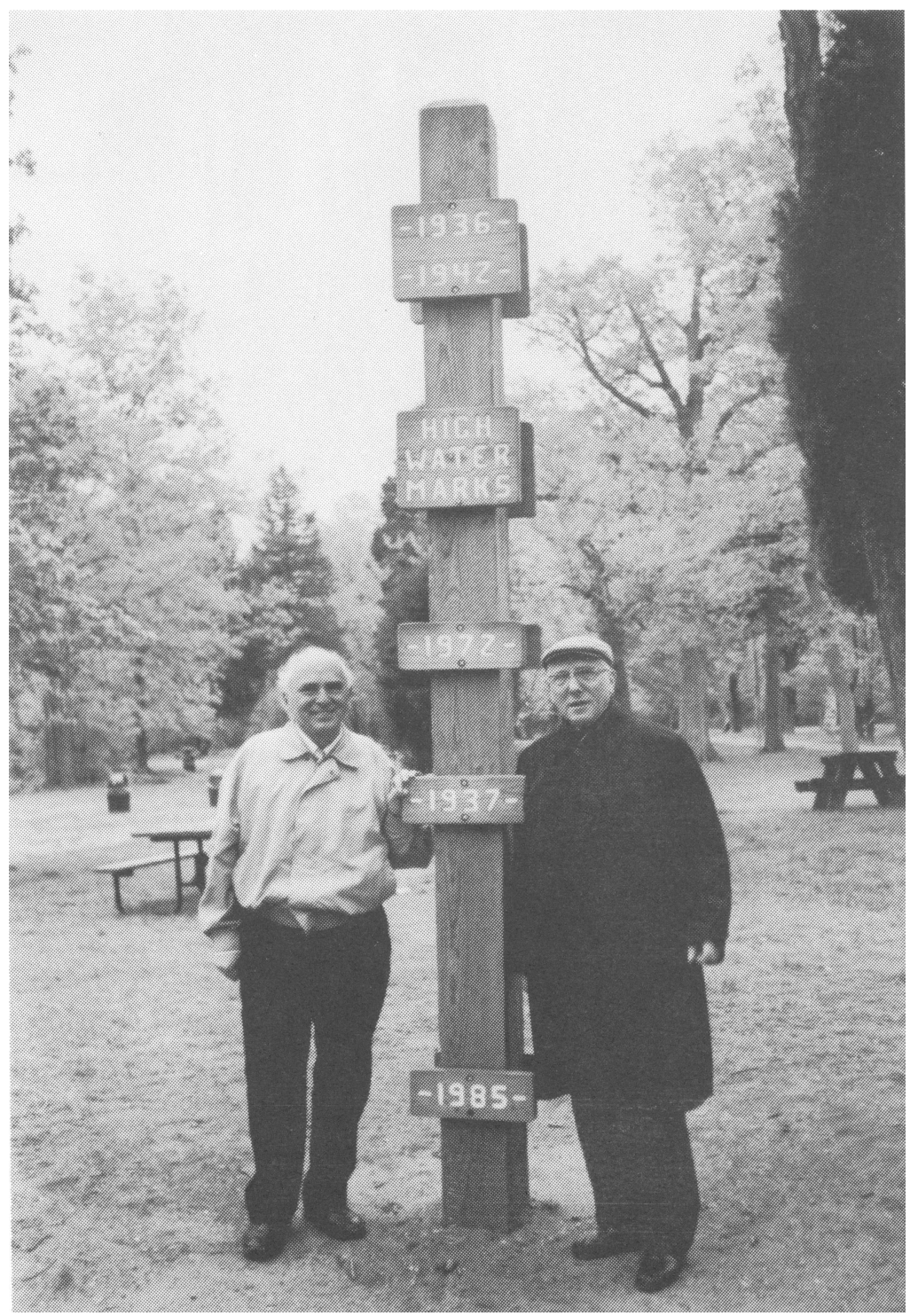

Ryszard Syski and Wim Cohen, Potomac Park, Virginia 1998. 
Wim will be missed by all probabilists. His demise is a huge loss to the probabilistic community. My personal description of Wim's life would be incomplete without stressing the constant love and support given to him by his wife Annette. Let the memory of their good times together bring her consolation.

\section{References}

[1] Cohen, J.W., On Ryszard Syski, JAMSA, 11:3 (1998), 223-224.

[2] Boxma, O.J. and Syski, R. [ed.], Queueing Theory and Its Application - Liber Amicorum for J.W. Cohen, North-Holland 1988.

[3] Boxma, O.J. and Syski, R., J.W. Cohen: his scientific career, CWI Quarterly $1: 3$ (1988), 73-80.

[4] Gani J. [ed.], The Craft of Probabilistic Modeling, Springer-Verlag 1986.

[5] Syski, R., A personal view of Queueing Theory, in Frontiers in Queueing [ed. by Dshalalow, J.H.], CRC Press 1997, 3-18.

[6] Syski, R., In Memoriam: Julian Keilson, JAMSA, 12:2 (1999), 101-103. 


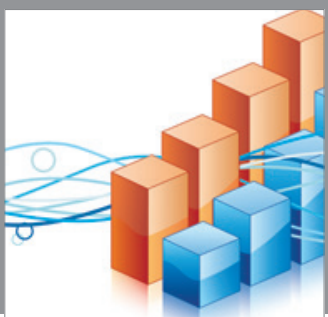

Advances in

Operations Research

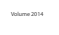

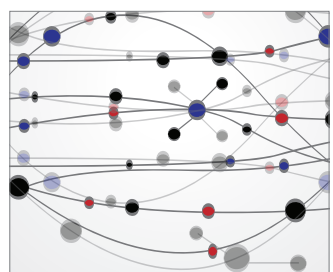

\section{The Scientific} World Journal
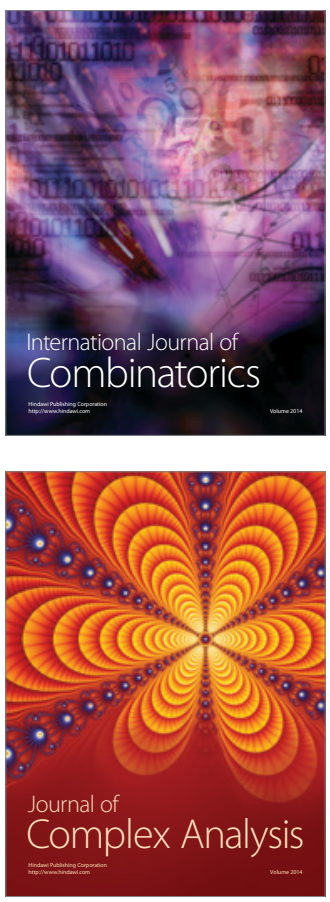

International Journal of

Mathematics and

Mathematical

Sciences
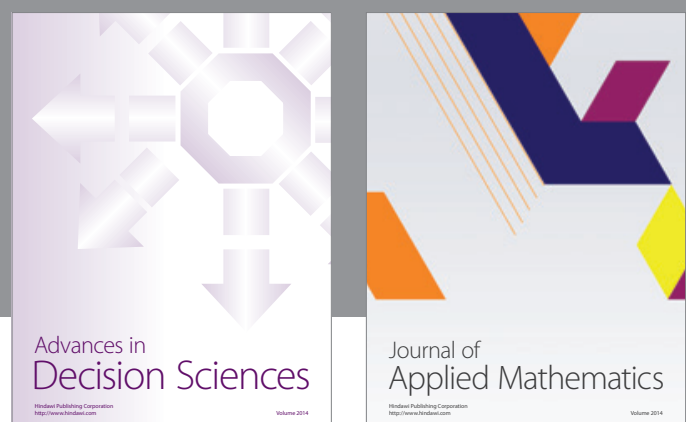

Journal of

Applied Mathematics
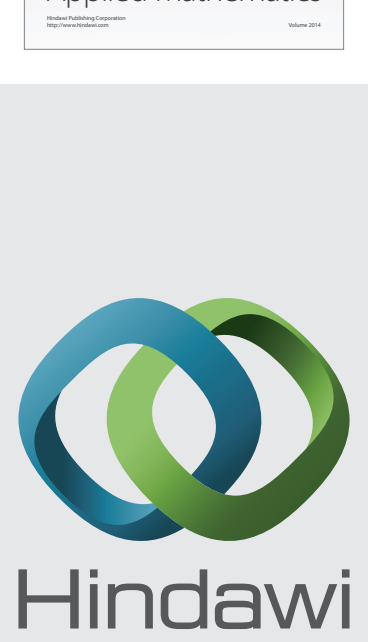

Submit your manuscripts at http://www.hindawi.com
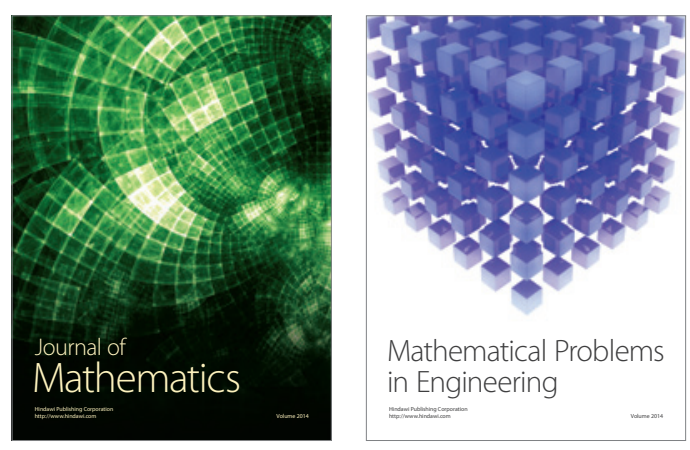

Mathematical Problems in Engineering
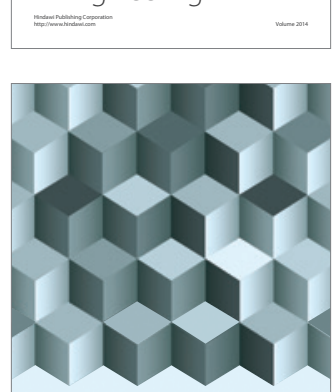

Journal of

Function Spaces
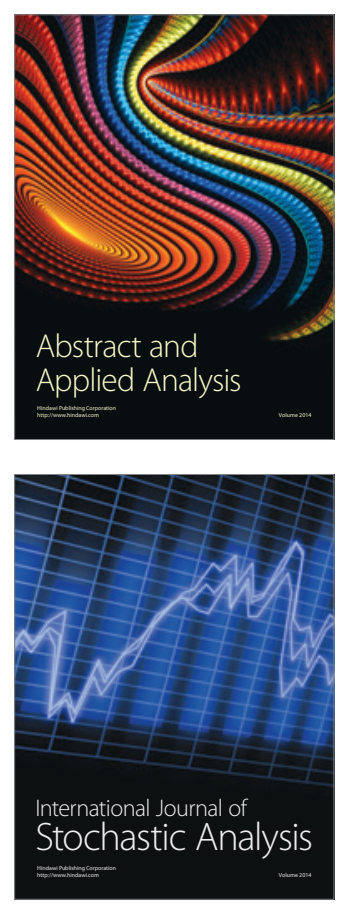

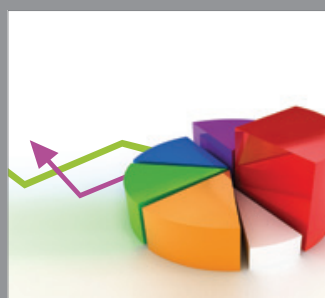

ournal of

Probability and Statistics

Promensencen
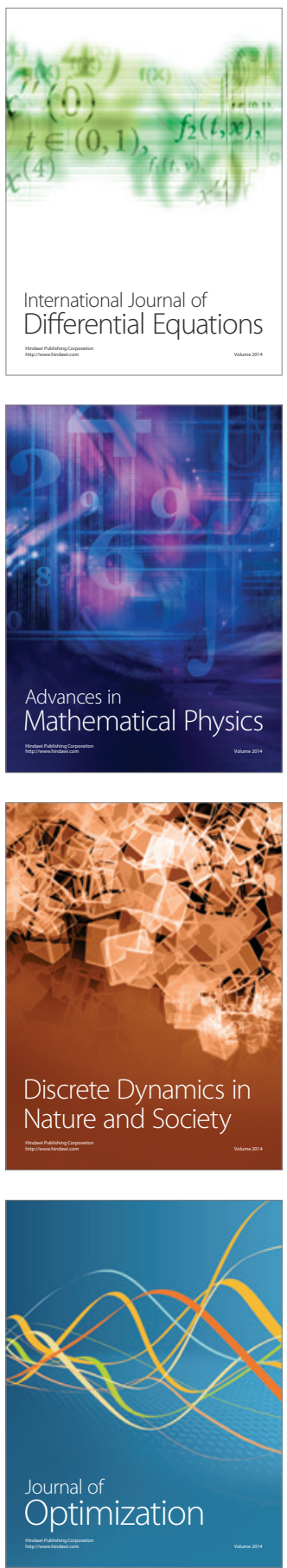